\title{
LES MISERABLES: VICTOR HUGO E O COTIDIANO DO SÉCULO XIX
}

\section{LES MISERABLES: VICTOR HUGO AND 19th CENTURY EVERYDAY LIFE}

Nathália Santos Pezzi ${ }^{1}$

Resumo: O presente artigo objetiva fazer uma breve análise de diversas questões sociais presentes na obra, como a miséria, a alteridade, o espírito cristão, os papéis de gênero e as classes sociais. Temas em geral ligados a um cotidiano não tratado pela historiografia de seu contexto. As personagens criadas por Hugo são representantes de posições sociais, temas políticos e valores. Desta forma, a partir da análise das personagens e do enredo, pretende-se trazer à tona as questões do cotidiano e, principalmente, a naturalização da miséria.

Palavras-chave: Victor Hugo, Romantismo, cotidiano.

Abstract: This article aims to make a brief analysis of several social issues present in the novel. Such as misery, otherness the Christian spirit, gender roles and social classes. Themes in general related to everyday life at the time, in general, not studied by the historiography of their context. The characters created by Victor Hugo are representatives of social positions, political themes and values. In this way, from the analysis of the characters and the plot, it is intended to bring out the issues of everyday life and the naturalization of miserliness.

Keywords: Victor Hugo, Romanticism, everyday life.

\section{Introdução}

Os miseráveis, uma das obras primas de Victor Hugo, teve sua primeira publicação em 1862, simultaneamente em diversas cidades, como Bruxelas, Milão, Roterdã e Paris. Desde seu lançamento até a atualidade, a

${ }^{1}$ Graduanda em História (Licenciatura e Bacharelado) pela Universidade Federal do Paraná. 
obra de 1.500 páginas que ainda encanta, foi traduzida para diversas línguas e adaptada para variados filmes, peças e séries. O musical faz parte da lista de peças da Broadway e mais recentemente, em 2012, a obra se viu novamente apresentada em um grande sucesso hollywoodiano, dirigido por Tom Hooper, ganhando 3 Oscars (FULKS, 2019).

Victor Hugo descreve minuciosamente seu contexto, fazendo-se muito fácil reformular mentalmente as diversas cenas descritas pelo autor. Quase como se fosse possível se sentir caminhando pelas ruas de Paris no século XIX, enxergando-se de perto toda a sua beleza e principalmente seu submundo de problemas sociais mais do que aparentes. Como ressalta Fúlvia Moretto, em seu texto Victor Hugo e o Romantismo, é relevante que este autor tenha vivido quase todo o século XIX: desde o Primeiro Império de Napoleão I, a Restauração, a Revolução de 1830, a Monarquia de Julho de Luís-Felipe de Orléans, a Revolução de 1848, o Segundo Império de Napoleão III e a Terceira República, a partir de 1870. Logo, Hugo teve uma ampla visão da sociedade francesa neste século (MORETTO, 1994).

O presente artigo objetiva fazer uma breve análise de diversas questões sociais presentes na obra, como a miséria, a alteridade, o espírito cristão, os papéis de gênero e as classes sociais, temas que são muitas vezes ligados a certas personagens. Hugo foi capaz de criar personagens representantes de posições sociais, temas políticos e valores, ainda que, num primeiro momento, essas mesmas personagens aparentem tentar demonstrar posições contrárias. Estas questões são todas ligadas ao cotidiano e tratam de personagens que na historiografia do século XIX não teriam grande visibilidade. 


\section{Victor Hugo e Les Miserables}

Victor-Marie Hugo (1802-1885) foi um poeta, dramaturgo e estadista francês, considerado um dos maiores nomes do Romantismo na França. Neste parágrafo tratarei brevemente da biografia do autor, inspirada na de Frazão (2019). Hugo nasceu na França, e devido ao posto de seu pai, general de Napoleão, passou grande parte de sua infância viajando. Teve seus estudos preparatórios no Liceu Louis le Grand, em Paris. Ainda muito jovem, em 1817, recebeu o seu primeiro prêmio, o Jeux Floraux de poesia da Academia Francesa, mais tarde recebeu também outras premiações. Em 1819, fundou a revista $O$ Conservador Literário, sendo o primeiro ensaio publicado um tributo prestado a Chateaubriand, considerado iniciador do Romantismo na França. Em 1841, Hugo é eleito para a Academia Francesa, e frequenta a corte das Tulherias. Em 1845 torna-se membro do senado francês, mostrando-se preocupado com a miséria do povo - tema que compõe toda a obra em questão -, razão pela qual funda e dirige o jornal $O$ Acontecimento. No entanto, quando eleito, Napoleão III viola a Constituição, Victor Hugo passa a ser perseguido ao tentar organizar a resistência à ditadura e se refugia em Bruxelas, onde se exila por de mais de 18 anos. É durante o exílio, momento apontado como o mais fértil de sua produção, que Hugo escreve a obra em questão: Les Misérables (1862), e outras obras célebres. ${ }^{2}$ Em 1870, numa reviravolta de eventos, Victor Hugo

${ }^{2}$ Entre as diversas obras deste autor, destaco os romances: Notre-Dame de Paris (1831) - também conhecido como: O Corcunda de Notre-Dame -, Cantos do Crepúsculo (1835), Os Castigos (1853), As Contemplações (1856), O Homem que $R i$ (1869), entre outras obras notáveis. 
é eleito deputado e se torna presidente da ala esquerda da Assembleia Nacional. Em 1876 se elege senador (FRAZÃO, 2019).

A obra de Victor Hugo oportunizou um espaço à retratação da vida cotidiana, ao contrário do apresentado pela historiografia do contexto, marcada pelo Positivismo. O Positivismo, herdeiro do Iluminismo, não enxergava a importância em escrever sobre o corriqueiro, o ordinário ou sobre a alteridade. Como afirma Barros (2011), o Romantismo foi a primeira filosofia da história a se opor a perspectiva universalizante do Iluminismo. Hugo expõe sua filosofia política na obra, tratando, também, o conflito na relação da pobreza com o Estado.

Moretto (1994) salienta que Victor Hugo fundamentava-se principalmente na História para escrever suas obras, como pode-se notar na exposição de diversos momentos históricos na obra em questão. ${ }^{3} \mathrm{E}$, com a história, a autora frisa que na literatura os dramas do romance são colocados dentro de uma realidade social, e a psicologia do personagem é revelada por diálogos verossímeis. A exemplo deste inserimento da realidade social no livro, cito o pronunciamento do autor sobre como se sentiu em 1815 , refletido na obra:

Esse 1815 foi uma espécie de Abril triste. As velhas realezas doentias evenenosas se cobriam de novas aparências. A mentira celebrou núpcias com 1789, o direito divino escondeu-se por trás de uma Carta, as ficções tornaram-se constitucionais, os preconceitos, as superstições e as segundas intenções com o artigo $14^{\circ}$ no coração, envernizaram-se de

${ }^{3}$ A exemplo da presença de Napoleão na obra - é esta personagem histórica que, no livro, dá a nomeação de Bispo de Digne ao Bienvenu. 
liberalismo. Simples troca de pele de serpentes. (HUGO, 2017: 493).

Resumindo muito brevemente esta grandiosa obra: trata-se da trajetória de Jean Valjean entrelaçada pela vida de Bienvenu, Fantine, Cosette, Javert, a família Thenardier, Marius Pontmercy, entre outras personagens. É também ligada a grandes acontecimentos históricos que se passaram na França pós-Revolução Francesa. A história é dividida em cinco volumes, cada um deles voltado para a trajetória específica da vida de cada personagem principal do romance. Jean Valjean, herói do romance, é um homem que já nascera condenado pela pobreza e depois à prisão - onde fica por 19 anos. Na prisão conhece o Inspetor Policial Javert, seguidor cego da justiça, que posteriormente o perseguiria incessantemente. Valjean, ao ser agraciado pela compaixão de Bienvenu, Bispo de Digne, retoma sua fé e promete viver uma vida honesta. Além disso, é fundamental o protagonismo de personagens femininas: Cosette e Fantine. Fantine após engravidar, ser abandonada e desempregada, se vê em extrema miséria, condenada a prostituição para sua sobrevivência e de sua filha, Cosette. Posteriormente, Valjean adota Cosette, sendo ela seu maior impulso para continuar sua fuga. Cosette apaixona-se pelo jovem revolucionário Marius, o que faz Valjean ser descoberto novamente. Javert, ao ser desvendado como espião nas barricadas de 1832, é salvo por Valjean. O gendarme ${ }^{4}$,

4 De acordo com o dicionário Larousse, a Gendarmerie é a força militar encarregada de zelar pela segurança pública e de assegurar a manutenção da ordem e a execução das leis em todo o território nacional, bem como aos exércitos. Javert é um gendarme, que, portanto, pode ser traduzido como um agente policial. (Tradução minha). A definição está disponível em: 
assim, acredita carregar uma dívida com Valjean e, ao mesmo tempo, não suportava deixar livre o "criminoso", assim suicida-se. Cosette cresce e casa-se com o jovem idealista Marius. Jean Valjean morre de velhice.

Porém, ao resumir a trama, compromete-se a riqueza detalhes tratada por Hugo que espelham a miséria, relacionada com o poder oficial. Além de estampar momentos históricos como a Batalha de Waterloo, a Restauração Bourbon, a Revolução de Julho (1830), o Motim de Junho (1832) e as suas barricadas da Rua Saint-Denis. É uma questão central perceber a naturalidade em que a miséria era tratada neste contexto histórico mais amplo. Hugo a trata como uma "visão sobre o outro" na qual a alteridade está concentrada na pobreza. Neste mesmo período outros romances que traziam esse tema como algo danoso ao desenvolvimento humano pleno começavam a ganhar espaço. Moretto (1994) destaca os romances de Zola, Flaubert e Maupassant, mas aponta que a maioria dos romances ainda era voltada a agradar apenas um público mais abastado.

A vida cotidiana destacada em Les Miserables é apresentada através das personagens. Neles é possível identificar os principais ideais do autor e também discussões políticas. As personagens podem ser vistas como representantes de discursos, de uma época, de condições sociais e de uma sociedade em construção. Como afirma Hartog (2017), em seu livro Crer em História, o romance era capaz de aproximar esta realidade da História, por causa de sua atenção aos detalhes, à incerteza, ao aleatório. O romantismo, como afirmam Lowy e Sayre (2015), teve como característica

$<$ https://www.larousse.fr/dictionnaires/francais/gendarmerie/36498> (acesso em 12 de maio de 2020). 
a subjetividade. Esta subjetividade é contraposta com a tendência do século XIX de que a história deveria ser racionalizada, retratando apenas os grandes acontecimentos, sem o desperdício de tempo com temas "menos relevantes". Assim, Hugo pretende retratar o cotidiano, a cultura, as formas sociais etc. através da singularidade de cada personagem.

Os fatos que vão ser relatados pertencem a essa realidade dramática e viva que as vezes o historiador negligencia por falta de tempo ou de espaço. Contudo, insistimos, nele é que está a vida, a palpitação, a agitação humana. Os pequenos detalhes (...) são, por assim dizer, a folhagem dos grandes acontecimentos e se perdem na distância da história. A época denominada das revoltas é pródiga em detalhes desse tipo (...). Mudaremos alguns nomes, pois a história conta e não denuncia, mas falaremos sobre coisas reais. Nas condições do livro que estamos escrevendo, mostraremos somente um lado, um episódio, com certeza dos menos conhecidos, dos dias 5 e 6 de junho de 1832; mas o faremos de tal modo que o leitor possa entrever, sob o sombrio véu que vamos levantar, a figura real dessa terrível aventura pública. (HUGO, 2017: 1394). ${ }^{5}$

Jean Valjean é a personagem que consolida os principais ideais do autor. Valjean é virtuoso, mas se degenera e perde sua fé devido às condições que lhe foram impostas. É o herói do romance, entretanto, neste momento é tratado de forma realista, num contexto em que era comum a idealização dos personagens em romances. Sua miséria havia lhe imposto o crime, e a prisão o havia endurecido. Concomitantemente, ao enredo do romance, Hugo pretende retratar a situação de miséria que muitos franceses

${ }^{5}$ Grifo meu. Neste trecho, Hugo apresenta sua intenção em trazer à tona o que, naquele momento, era deixado de lado pelos historiadores: o cotidiano, a cultura, as formas sociais etc. 
viviam, em que os gastos com a política externa francesa tinham aumentado devido à busca de glória política de Napoleão.

Ao roubar pão para alimentar sua família, Valjean é condenado a cinco anos de prisão. Em virtude de suas tentativas de fuga e mau comportamento na cadeia sua pena é aumentada para 19 anos. O miserável tinha consciência de que seu crime havia sido ínfimo se comparado com a sua pena. Hugo pretendia denunciar, com certo realismo - uma tendência literária que já estava em pauta no contexto - as injustiças do poder judiciário. É também uma crítica à forma desumana com que se dava o tratamento ao "outro", abordando as condições impostas aos prisioneiros, a realidade do duro trabalho forçado, que no caso de Valjean se deu nas galés francesas do século XIX.

Este personagem do miserável atravessa o século. No século XX, George Orwell, em seu artigo "Um dia na vida de um vagabundo" (2011), mostraria como esta tendência de naturalização da miséria ainda se repetia no continente europeu no século seguinte, neste caso, na Inglaterra. É relevante como Orwell parece, até mesmo, estar se referindo à história do miserável retratado por Victor Hugo:

É um círculo vicioso: se ele não mendiga, morre de fome; se mendiga infringe a lei. (...).

Por fim, o vagabundo, que não cometeu nenhum crime e que, no fim das contas, não passa de uma vitima do desemprego, está condenado a levar uma vida mais miserável que a do pior criminoso. Ele é um escravo com uma aparência de liberdade que é pior do que a mais cruel escravidão. (ORWELL, 2011: 45) 
Ainda que tratem de um mesmo personagem histórico que atravessou as barreiras do tempo, Hugo e Orwell trazem soluções muito diferentes ao mesmo problema. Diferentemente de Orwell, Hugo não prega a revolução como uma solução viável. Através de Valjean percebe-se que é o espírito cristão que o dignifica, tirando-o da miséria e dando-lhe uma nova chance. $\mathrm{Na}$ obra é essencial o papel da providência divina tratada através da personagem Bienvenu, o Bispo de Digne. Esse religioso, que teria recebido o título de bispo ao encontrar-se com Napoleão, é uma personagem retratada pela sua benevolência e seu desejo verdadeiro de se desligar dos bens materiais e fazer o bem. O Bispo, inclusive, criticava demasiadamente outros bispos que conhecia, que ao invés de seguirem realmente os mandamentos da Igreja, viviam pela ganância.

Em 1815, mesmo ano da Restauração Francesa, também conhecida por Restauração Bourbon, Valjean conhece o Bispo de Digne, única pessoa que o ampara quando todos o recusaram a ajuda, em razão de sua marca de criminoso. Valjean, entretanto, trai a confiança do bispo e rouba sua prataria e, consequentemente, é descoberto. No entanto, Bienvenu mente aos policiais, afirmando tê-lo dado a prataria, salvando-o de imediatamente voltar às galés. Desta forma, declara estar "comprando a alma" de Valjean, que após o episódio recobra a fé e compromete-se com a benevolência, honestidade e honra. A questão da providência divina, principalmente através de um membro da Igreja Católica, demonstra claramente os valores cristãos de Victor Hugo ${ }^{6}$.

${ }^{6}$ O papel da Providência Divina é fundamental na obra. Inicialmente através do Bispo Bienvenu, que na obra representa a misericórdia e a compaixão. O papel da providência se mostra ainda presente, nas inúmeras fugas inacreditáveis de Valjean 
Lowy e Sayre (2015), em seu livro Revolta e Melancolia, afirmam ser característica do romantismo a "autocrítica da modernidade", sendo esta modernidade caracterizada pela Revolução Industrial. Alguns traços dessa crítica à modernidade delineados por estes autores podem ser identificados no romance de Hugo, como a crítica da individualidade egoísta dada pela dissolução dos vínculos sociais e também a crítica da desumanização do ser humano. Um exemplo é o trecho em que o autor pinta a miséria vista nas ruas de Paris:

Na moderna civilização, ainda tão incompleta, não é muito anormal essa destruição de famílias extinguindo-se na sombra, sem saber para onde vão os filhos, deixando cair as entranhas em meio a praça pública. Daí esses destinos obscuros. Isso se chama, pois tão triste realidade produziu uma locução, ser lançado às sarjetas de Paris (HUGO, 2017: 784).

Entretanto, Hugo não parece culpar a expansão industrial completamente por esta miséria, ao mesmo tempo esta expansão parece algo positivo e negativo, já que Jean Valjean consegue sua vida nova através de sua fábrica, chegando a virar prefeito com seu pseudônimo: Madeleine. Fábrica que construiu por meio das benesses dadas pelo Bispo. Logo, é através de Jean Valjean que Victor Hugo apresenta sua própria

e também em outros personagens. A mensagem passada por Hugo é clara: o espírito cristão seria a forma de dignificação da alma. A influência da religião é nítida nesta obra e em outras obras de Hugo, em que os valores cristãos fazem parte da idealização de seus heróis. O autor francês teve, desde muito cedo, contato com estes valores idealizados, cresceu com uma educação católica e mais tarde, durante seu exílio, tornou-se espírita. Cf. SCHNEIDER, Maria do Carmo M. Victor Hugo: a face oculta de um gênio. Anais do XIII Congresso da Associação Brasileira de Literatura Comparada. Acesso em 12 de maio 2020). 
concepção de que o trabalho dignifica o homem e a sociedade. $\mathrm{O}$ francês apresenta Valjean como um empregador justo - ainda que não estivesse presente em momentos cruciais em sua fábrica, como o momento de demissão de Fantine. Valjean era uma exceção, já que o momento era de dissolução de vínculos sociais.

Lowy e Sayre (2015) descrevem diversos tipos ideais de românticos . Hugo, na obra em questão, devido a sua perspectiva crítica dentro do movimento romântico, parece encaixar-se no tipo ideal do Romantismo reformador dos autores, posto que não propõe uma volta ao passado e enxerga os problemas de sua sociedade, porém não critica completamente a revolução industrial. Esta noção sobre o trabalho parece estar ligada a noção de progresso na modernidade, principalmente pela tendência positivista que influenciou demasiadamente o século XIX.

A questão do progresso relacionado a ciência, também do nacionalismo - visões muito ligadas ao positivismo - e como eram vistas as revoluções também são tratadas na obra. Um exemplo é o diálogo de Bienvenu com o senhor G., um octogenário convencionalista, passagem na qual conversavam sobre o voto pela morte do rei durante a Revolução Francesa:

- Quero dizer que o homem tem um tirano, a ignorância. É pela morte desse tirano que dei o meu voto, desse tirano que inventou a realeza, autoridade nascida da mentira, enquanto a ciência é a autoridade que surge da verdade. O homem deve ser governado pela ciência. - E pela consciência - acrescentou o Bispo. - Confunde-se com a ciência. (...). O convencionalista prosseguiu: - Quanto a Luís XVI, não votei pela sua morte. Não me julgo com o direito de matar um 
homem, mas sinto o dever de exterminar o mal. Votei pelo fim do tirano, isto é, pelo fim da prostituição da mulher, da escravização do homem, da ignorância da juventude. Votando pela república, votei por tudo isso. Votei pela fraternidade, pela concórdia, por uma nova aurora. Acelerei a queda de preconceitos e erros. $\mathrm{O}$ fim dos preconceitos e falsas doutrinas gera a luz. Nós fizemos a ruína do velho mundo, e esse mundo velho, vaso de misérias, derramando-se sobre o gênero humano, transformou-se numa taça de alegrias. - Tristes alegrias - disse o Bispo. - Pode dizer, se quiser, alegria perturbada, e hoje, após a volta fatal do passado que se chama 1814, é melhor dizer alegria desaparecida! Infelizmente, a obra não estava perfeita, concordo; derrubamos as aparências externas do Antigo Regime, mas não lhe suprimimos as ideias. Não basta destruir os abusos; é preciso mudar os costumes. Desapareceu o moinho, mas o vento ainda sopra. (...). (HUGO, 2017: 72).

Através deste diálogo, é possível compreender que Victor Hugo entendia que apenas a Revolução não tinha mudado a forma de viver do povo francês, seria necessário um processo longo para que mudasse a cultura, para que a miséria deixasse de ser vista como algo cotidiano.

Conforme Hobsbawm (1997), em seu livro A Era das Revoluções, estas aconteceram devido a uma falta de sincronia dos sistemas políticos com a rápida mudança social do contexto abordado, algo também evidenciado quando Victor Hugo fala da Batalha de Waterloo:

Uma força superior ao homem já o havia preestabelecido. Daí o pânico, daí o espetáculo de tantas grandes almas entregando as armas. Os que haviam vencido toda a Europa caíram vencidos, nada mais tendo a fazer ou a dizer, sentindo naquela sombra uma presença terrível. Hoc erat in fatis. Naquele dia, mudou-se a perspectiva do gênero humano. Waterloo é o gonzo sobre o qual gira o século XIX. O desaparecimento do 
grande homem era necessário para o desenvolvimento do grande século (...). (HUGO, 2017: 476).

O lugar das mulheres neste contexto de miséria naturalizada pode ser retratado pela personagem de Fantine. A personagem era ainda uma jovem ingênua quando se apaixona pelo jovem estudante Tholomyès, que era proveniente de uma família rica - ao contrário da jovem. Todavia, o estudante apenas a encarava como uma "brincadeira" e a deixa. Algo que também retrata o inserimento dos jovens em classes, ou seja, Hugo retrata que por ser pobre, a garota era vista como descartável ao jovem rico. Fantine encontrou-se grávida e sozinha - o que era considerado imoral à época. A jovem então se vê obrigada a entregar sua filha Cosette ao casal Thénardier, que por muito tempo à trapacearam, exigindo cada vez mais dinheiro. Esse casal na obra representa o pecado da ganância, evidenciando que a influência cristã na obra do autor francês não se encerra apenas na figura do bispo, mas perpassa todos os personagens, tecendo a trama. Alguns representando afrontas à moralidade cristã, como Fantine, outros representando a possibilidade de expiação dos pecados, como Jean Valjean.

Seguindo o enredo, Fantine consegue um trabalho na fábrica de Madeleine — pseudônimo de Valjean —, felicidade que dura pouco, já que quando outras operárias descobrem que era mãe solteira, conseguem a sua demissão, já que não queriam ser associadas a ela. Michelle Perrot, em seu livro As mulheres ou os silêncios da História, ressalta que as mulheres neste contexto eram vistas pelos industriais como uma força de trabalho desejada: mão de obra barata. A historiadora destaca, entretanto, a contradição: as mulheres operárias eram mal vistas pela sociedade e pela 
imprensa, dado o seu trabalho fora do lar. Assim, ao mesmo tempo em que se beneficiava-se do trabalho feminino, o ideal da mulher burguesa condenava-o (PERROT, 2017).

A prostituição é ainda um tema mais profundo na questão de gênero tratada por Victor Hugo. Vista no contexto como escandalosa, obscena e desprezível, as mulheres que se prostituíam eram tratadas como sujas e indignas. Michelle Perrot expõe que a relação com a sexualidade feminina em geral era a de controle e repúdio (PERROT, 2017). Entretanto, no caso de Fantine, a prostituição aparece como a única alternativa de uma mãe que precisa cuidar de sua filha supostamente doente e está disposta, como uma mãe que ama incondicionalmente, a fazer qualquer coisa por sua filha. Fantine, ainda que na pele de uma prostituta — papel feminino antagônico do ideal burguês —, representa o ideal feminino de mãe, sacrificando-se pelo bem de sua prole. Novamente o papel da providência se mostra presente nos últimos momentos da vida de Fantine, que, ainda que prostituta, era uma mãe ideal (que não deixa de ser a mãe ideal também em valores cristãos). Valjean jura à Fantine em seu leito de morte que cuidaria de Cosette, menina que faz com que Valjean recobre novamente as esperanças.

O conflito na relação com o Estado é encarnado pela personagem de Javert, um gendarme, o agente da polícia cuja característica principal é a cega fé no sistema legislativo, que vê como única fonte de razão e justiça. Javert, como representante do poder oficial, repudia a miséria, combate ao crime e segue a lei inflexivelmente. 
A forma como o Estado tratava a miséria, sem a percepção de que os problemas sociais estavam ligados a falta de fornecimento das necessidades básicas, apenas parecia fazer com que aumentasse a violência. Estado este que pouca empatia parecia ter por aqueles que viviam na miséria e cujas leis pareciam apenas beneficiar os mais ricos. Assim, diferentemente do que esta personagem acreditava, a lei parecia agir em favor da injustiça. Por consequência, aplica-se novamente a falta de continuidade das ideias democráticas com o sistema político do contexto evidenciado por Hobsbawm (1997).

O trágico conflito de 1832 é narrado em detalhes por Hugo, momento da luta de todos os "miseráveis" contra o sistema político estabelecido, uma vez que até os personagens que possuem alguma divergência de pensamento estão lutando juntos, por uma Paris livre e mais igualitária. Conforme Hobsbawm (2017), estes conflitos pós napoleônicos se mostravam menos planejados, diferentemente da Revolução Francesa. Hobsbawm frisa que a onda revolucionária de 1830 marca a derrota definitiva dos aristocratas pelo poder burguês na Europa Ocidental. Marius Pontmercy e seus amigos eram um grupo de jovens estudantes, que abraçam a causa dos mais necessitados. Em um discurso, Enjolras, amigo de Marius Pontmercy, declararia a favor do conflito. Nesse discurso, percebe-se a crença no progresso aliado à ciência e a Revolução Industrial e, também, a noção de que a história humana "caminha" para a igualdade.

Dominamos a hidra, agora chama-se vapor; dominamos o dragão, agora chama-se locomotiva; estamos prestes a dominar o grifo, já o temos em nosso poder, agora chama-se balão. (...) Coragem e avante! Cidadãos, para onde iremos? 
Para a ciência transformada em governo, para a força das coisas transformada na única força acessível a todos, para a lei natural recebendo sanção e penalidade em si mesma e promulgando-se pela evidência, para uma aurora de verdade que corresponde à aurora do dia. Caminhamos para a união dos povos, para a unidade do gênero humano (...) Cidadãos, o século XIX é grande, mas o século XX será feliz. Então nada haverá de semelhante a velha história; ninguém terá de temer, como atualmente, uma conquista, uma invasão, uma rivalidade a mão armada entre as nações (...). Entendamo-nos a respeito da igualdade, porque se a liberdade é o ápice, a igualdade é a base. A igualdade, cidadãos, não é absolutamente toda a vegetação à mesma altura, uma sociedade de longas hastes de ervas e de carvalhos-anões; uma aproximação de invejas cortando-se mutuamente; é, civilmente, as mesmas oportunidades para todas as aptidões; politicamente, todos os votos com idêntico peso; religiosamente, todas as consciências com os mesmos direitos. A igualdade tem um órgão: a instrução gratuita e obrigatória. (HUGO, 2017: 1562-1563).

Estas ideias assemelham-se com as de Michelet, que escreve no mesmo período que Victor Hugo. Como demonstra Lima (2013), Michelet era "o grande historiador da nação francesa" e pretendia retratar o "espírito do povo", levando em conta, assim como fez Hugo, o individual do cotidiano, do povo e da cultura. E, como apontado por Santos (2001), a Revolução para Michelet era detentora do segredo da liberdade, assim, a França liderava este caminho. Da mesma forma que Michelet, Hugo trata deste espírito do povo, em especial o francês. Há um nacionalismo intrínseco na obra, junto de uma visão de que esta nação caminhava para a liberdade das amarras do então sistema político vigente. 


\section{Considerações finais}

Les miserables põe em evidência, através das personagens e dos desvios de caráter dessas personagens, uma variada gama de opiniões, sentimentos, posições políticas, posições sociais e econômicas e sua relação entre si e com os valores em voga àquele momento na França, caracterizando-se como uma rica fonte para a História. A pertinência dessa grande obra de Victor Hugo é sentida em perspectivas muito além da História e da Literatura, mas em diversos campos do conhecimento, sendo de grande valia para o estudo do Direito, da Psicologia, da Antropologia, da Sociologia, entre outros.

Os debates historiográficos que podem partir desta obra de Victor Hugo são diversos e abundantes, mas o autor havia já destacado o que pretendia trazer à tona, causando debates em seu próprio contexto:

Enquanto os três problemas do século - a degradação do homem pelo proletariado, a prostituição da mulher pela fome, e a atrofia da criança pela ignorância - não forem resolvidos; enquanto houver lugares onde seja possível a asfixia social; em outras palavras, e de um ponto de vista mais amplo ainda, enquanto sobre a terra houver ignorância e miséria, livros como este não serão inúteis. (HUGO, 2017).

Victor Hugo retrata o século XIX, na França, como o dos miseráveis, um povo "sem voz" que se fortalece como um grupo. Os diversos acontecimentos históricos — os quais o autor francês pôde vivenciar inseridos em Les miserables são palco para esta união. Além disso, estes acontecimentos, descritos da forma que foram, demonstram a visão do autor sobre estes. Também, os discursos proferidos sobre estes 
acontecimentos ao longo da obra representavam as noções sobre eles em classes diversas. A obra, visto que seu autor se empenhou a descrever os ínfimos detalhes e a retratar grupos — que até então não tinham destaque —, esclarece diversas práticas e significados de diversos grupos sociais, sua cultura e sua linguagem que representam poderes econômicos, políticos e visões de mundo.

$\mathrm{O}$ autor faleceu em Paris e em seu testamento deixou cinquenta mil francos aos pobres, pediu preces de todas as almas - e não a Igrejas - e afirmou acreditar em Deus. Foi sepultado em $1^{\mathrm{o}}$ de junho no Panteão, o monumento fúnebre dos heróis nacionais (FRAZÃO, 2019). Este seu último ato de vontade apenas reforça os ideais que tanto defendeu em sua obra: sua visão humanizada da alteridade, a representação da subjetividade na história, seu sentimento nacionalista da história francesa, seus valores cristãos.

\section{Bibliografia}

BARROS, José D’Assunção. Considerações sobre o Paradigma Positivista em História. In: Revista Historiar. Universidade Estadual Vale do Acaraú v.4. n. 4 (jan./jun. 2011). Disponível em: <www.uvanet.br/revistahistoriar $>$.

FRAZÃO, Dilva. Resumo da Biografia de Victor Hugo. Disponível em: $<$ https://www.ebiografia.com/victor_hugo $>$. Acesso em: 30/05/2019.

HARTOG, François. Do lado dos escritores: os tempos do romance. In: Crer em História. Belo Horizonte: Autêntica, 2017. p. 127-174.

HOBSBAWM, Eric J. A era das revoluções: Europa 1789-1848. Tradução: TEIXEIRA, Maria T. L.; PENCHEL, Marcos. Rio de Janeiro: Paz e Terra, 1997. 
HUGO, Vitor. Os miseráveis. Tradução: BARROS, Frederico O. P. B. (1 ed). São Paulo: Companhia das Letras, 2017.

LAROUSSE DICTIONNAIRE. Définition de Gendarmerie. Disponível em: https://www.larousse.fr/dictionnaires/francais/gendarmerie/36498. Acesso em 12/05/2020. (Tradução minha).

LIMA, Michelle Schreiner. A constituição da história como ciência: de Ranke a Braudel. Petrópolis: Vozes, 2013.

LOWY, M e SAYRE, R. Revolta e melancolia. São Paulo: Boitempo, 2015.

MORETTO, Fúlvia M. L. Lettres Françaises. São Paulo: Editora UNESP, 1994.

ORWELL, George. Como morrem os pobres e outros ensaios. Tradução: Pedro Maia Soares. São Paulo: Companhia das Letras, 2011.

PERROT, Michelle. As mulheres ou os silêncios da História. Tradução: RIBEIRO, Viviane. São Paulo: EDUSC, 2005.

PERROT, Michelle. Os Excluídos da História: operários, mulheres e prisioneiros. Tradução: BOTTMANN, Denise. Rio de Janeiro/São Paulo: Paz \& Terra, 2017.

SANTOS, Afonso Carlos Marques dos. Nação e História: Jules Michelet e o paradigma nacional na historiografia do século XIX. Revista de História, $\mathrm{n}^{\mathrm{o}}$ 144, 2001. p. 151-180.

SCHNEIDER, Maria do Carmo M. Victor Hugo: a face oculta de um gênio. Anais do XIII Congresso da Associação Brasileira de Literatura Comparada. Acesso em 12 de maio 2020.

Recebido em: 17/08/2019

Aceito em: 14/05/2020 